\title{
Integrated application of flow pattern map for long-term gas lift optimization: a case study of Well T in Indonesia
}

\author{
Silvya Dewi Rahmawati ${ }^{1}$ - Steven Chandra ${ }^{1}$ Prasandi Abdul Aziz ${ }^{1}$. Wijoyo Niti Daton ${ }^{1} \cdot$ Ardhi H. Lumban Gaol $^{1}$
}

Received: 24 September 2019 / Accepted: 9 December 2019 / Published online: 8 January 2020

(c) The Author(s) 2020

\begin{abstract}
Gas lift optimization has been a classic problem since its inception. The problem with currently practiced optimization, the gas lift performance curve (GLPC), was the sole requirement for exhaustive calculation that has to be performed every time changes to the reservoir are acknowledged. The approach of mechanistic modeling has been proven to be a powerful tool to complement the analysis of GLP curves, especially in complex, multi-well gas lift system. This publication offers a new approach in modeling the progression of flow pattern map (FPM) in case of reservoir pressure decline. The findings presented in this publication encourage the hypothesis that FPM can be used with minimum alteration should there be any changes in reservoir pressure.
\end{abstract}

Keywords Gas lift · Performance curve $\cdot$ Mechanistic modeling $\cdot$ Flow pattern map · Optimization $\cdot$ Correction factor

\section{Introduction}

Indonesia's oil production has been on a less favorable trend lately, where current production is not complemented with new reserve discovery and several newly developed fields are not producing in accordance with its previously designed schedule. Therefore, marginal oil fields that have been producing for tens of years have to be optimized in order to sustain the nation. Gas lift currently holds as one of the most prominent artificial lift methods not only in Indonesia, but also worldwide due to its long history of practice and success stories. The beneficial properties of gas lift, such as having almost no moving part and versatility in a wide range of well specifications and reservoir properties, coupled with relatively low operational expenditure are deemed to be ideal for Indonesia's oil production rejuvenation (Arachman et al. 2017; Aprilian et al. 2003).

Current industrial practices have divided two different approaches in optimizing gas lift design. The first one packaged as engineering optimization where new types of equipment, injection method, and gas lift valve placement are optimized based on new findings and technologies (Glass

Steven Chandra

steven@tm.itb.ac.id

$1 \quad$ Petroleum Engineering Program, Institut Teknologi Bandung, Jalan Ganesha No 10, Bandung, Indonesia
1975; Mukherjee and Brown 1986; Asheim 1988; Betancourt et al. 2002; Decker 2007). These approaches have been developing as an answer to increase practicality and long-term use of gas lift systems. The second approach is mainly developed in conjunction to the need for field wide gas lift optimization and scheduling or injection allocation, with sophisticated algorithms taken from the field of nonlinear optimization, machine learning and genetic algorithm (Ranjan et al. 2015; Wang and Litvak 2008; Lu and Fleming 2011; Posenato and Rosa 2012; Samier 2010; SalazarMendoza 2006; Deng et al. 2019).

The simplest, yet the most highly accepted practices in optimizing gas lift have been revolving around the concept of gas lift performance curve (GLPC), an extended application of nodal analysis, in which a single curvature projecting liquid (hydrocarbon and/or water) recovery in a well as a function of incremental gas injected. Several novel approaches have been disseminated to enrich the concept and application of GLP curves, namely quantification of the curves and observation of curvature behavior, pioneered by a set of publications from Kanu et al. (1981) and augmented by Nishikiori et al. (1989), Alarcón et al. (2002), Fang and Lo (1996) and Schmidt et al. (1990). However, the GLPC, derived from a static circumstantial-based evidence of nodal analysis, is known and proven to be highly repetitive method where changes in production dynamics will require multiple calculations of GLP curves. As production parameters are 
known and accepted to be changing in a highly dynamic situation, minuscule alterations of GLP curves for every change are not operationally and economically feasible due to difficulties in data gathering and its adverse effect into reservoir dynamics. Mian (1992) presented an improvement of GLPC concept, using simpler term, gas utilization factor (GUF) in which a plot of gas injected as a function of oil produced is plotted as a function of monetary value of the operation itself. However, this approach is not novel to the aspects of production engineering and yet only presented another complication due to the dynamic oil and gas price. Therefore, this publication aims to deliver another point of view in reducing uncertainties in GLPC forecast and production modeling.

Basic researches related to multiphase fluid flow in gas lift system is not commonly encountered recently, namely due to the relatively established operational procedure of gas lift system, providing less incentive to perform researches in highly uncertain areas. Multiphase flow research does provide a new perspective in a previously thought to be well-understood phenomenon such as liquid loading and slugging phenomenon, rendering new comprehension and more detailed mapping of the problem itself (Veeken and Belfroid 2011).

The application of mechanistic modeling, an approach that identifies pattern, timed changes, routine alterations of a dynamic system, has never been prominently applied in the aspects of petroleum engineering, mainly due to its complicated nature. Many researches related to mechanistic modeling have only been limited to basic researches in fluid flow in pipes (Taitel and Dukler 1976; Barnea 1987; Taitel and Barnea 1990). It is known that mechanistic modeling often requires high understanding in fluid physics, as well as rigorous mathematical process. However, mechanistic modeling does offer more realistic model due to its nature of observation-based model coupled with mathematical modeling.

Several models have been developed for multiphase flow model in pipe, namely the Taitel and Dukler (1976) which is augmented by Taitel et al. (1980) for general applications of general pipeline system and downhole casing/tubing system. These models basically laid the foundation for Ansari et al. (1990)'s model which defines flow patterns into 4 distinct flow patterns, shown in Fig. 1, which laid good foundation for further researches in flow pattern mapping.

The 4 distinct flow patterns shown above can be utilized as a benchmark in defining ideal flow pattern for gas lift operations. However, these flow patterns have to be mathematically and physically quantified in order to increase its utilization. The study is extended by Shoham (2006) in developing a simple graphical function to determine flow pattern region as a function of superficial liquid velocity and superficial gas velocity, named as flow pattern map (Daton
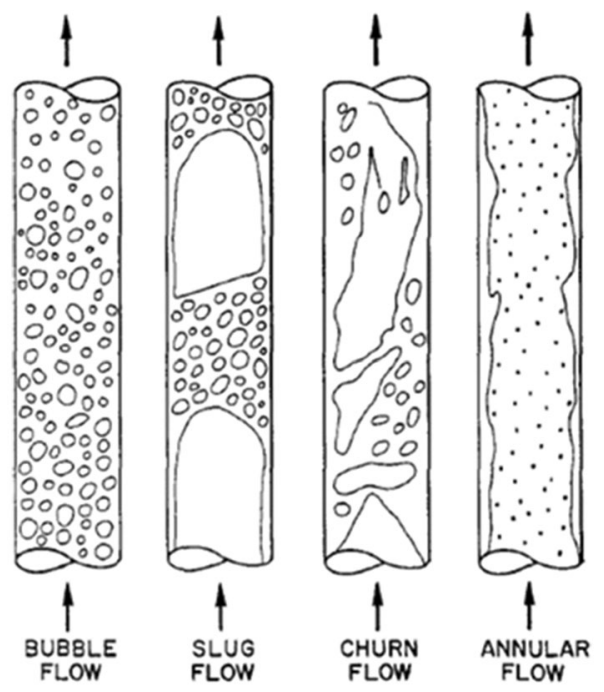

Fig. 1 Flow pattern in multiphase flow. Reproduced from Ansari et al. (1990)

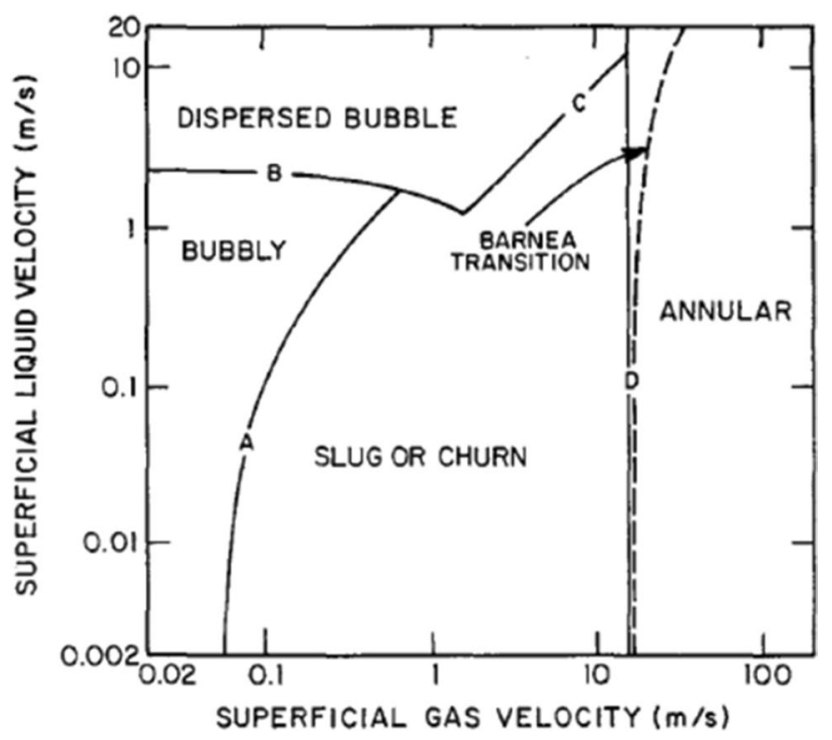

Fig. 2 Typical flow pattern map. Reproduced from Shoham (2006)

et al. 2019; Lumban Gaol et al. 2019). Therefore, the concept of superficial liquid velocity is then introduced to the pattern mapping, shown in Fig. 2, rendering a flow pattern map (FPM) for simple, versatile use of flow pattern dynamics in gas lift optimization.

\section{Methodology}

This study is an extension of Daton et al. (2019) and Lumban Gaol et al. (2019)'s study where the application of flow pattern map (FPM) is extended to be utilized in gas 
Fig. 3 Flow pattern map for gas-lifted wells. Reproduced from Daton et al. (2019)

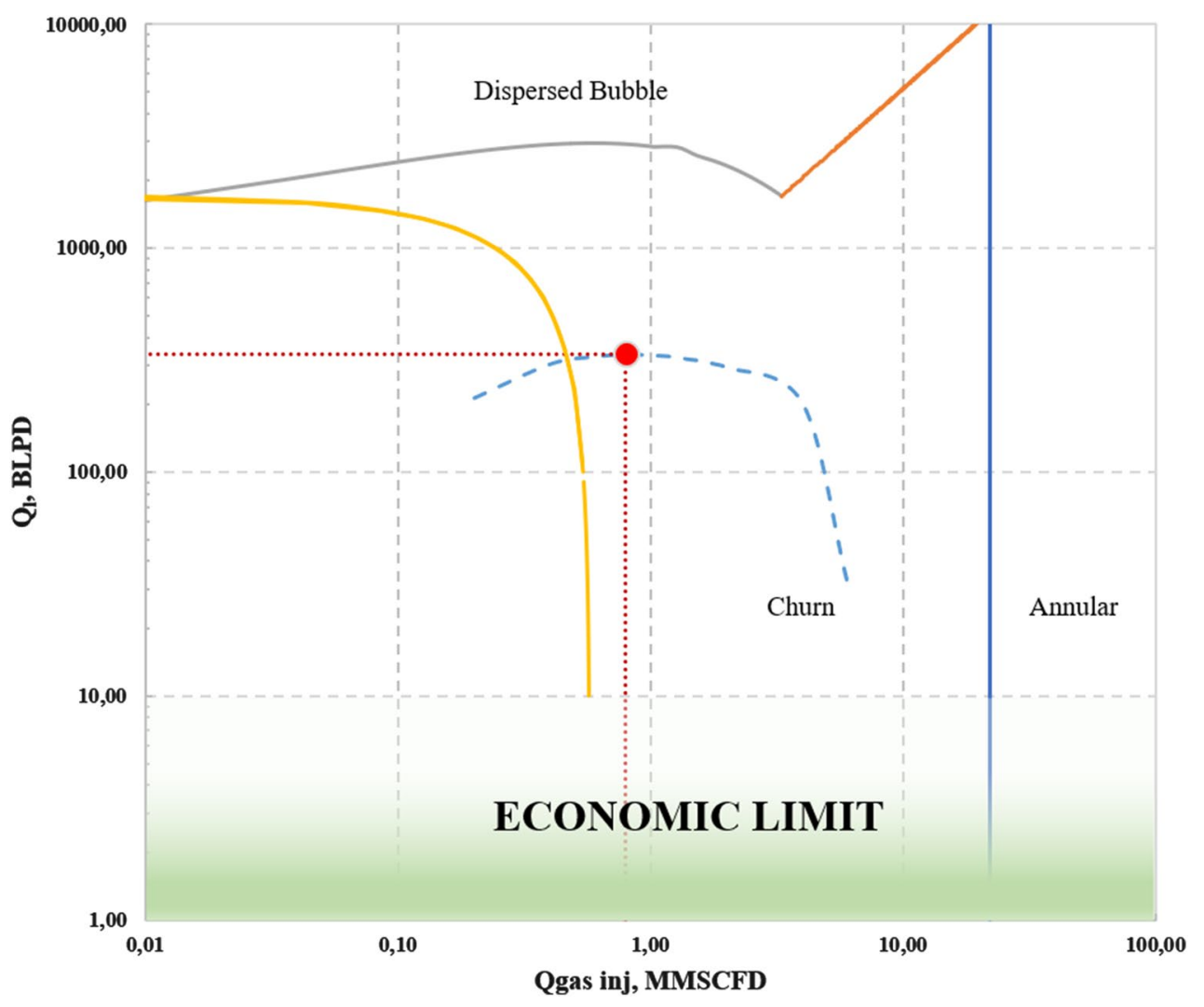

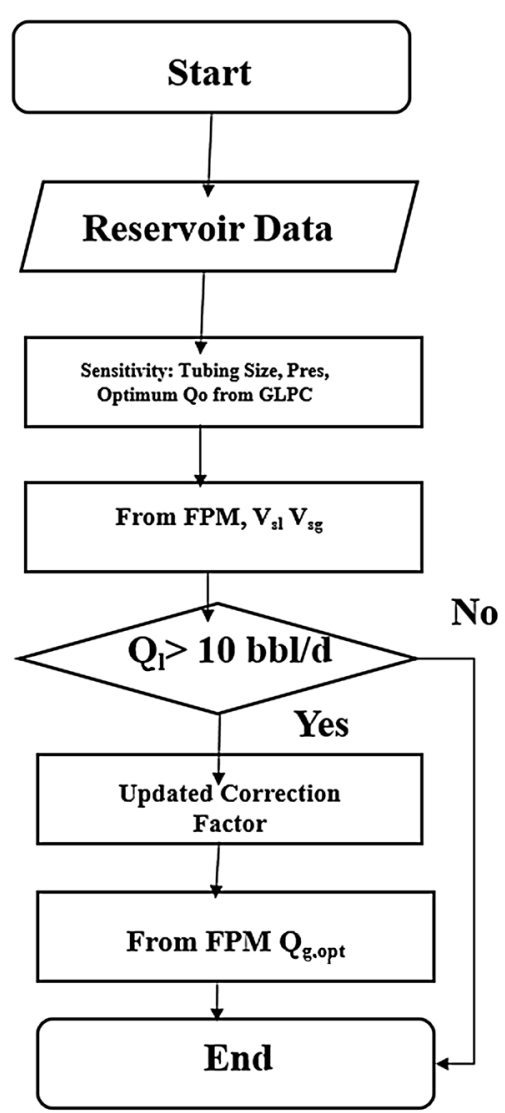

Fig. 4 Flowchart for FPM and correction factor utilization lift optimization. Previous studies performed by the aforementioned authors have indicated that FPM can be used in conjunction with GLP curves to verify the optimum amount of injected gas lift, shown below.

As shown in Fig. 3, it is worth noting that the application of FPM can be used as an auxiliary tool to complement the GLP curve (blue dashed line. The red dot represents the optimum gas lift injection rate which results in the highest oil rate at certain condition) analysis in gas lift

Table 1 Well $\mathrm{T}$ basic data

\begin{tabular}{|c|c|c|c|c|}
\hline Parameters & & Value & Units & Remarks \\
\hline \multirow[t]{2}{*}{ Tubing } & OD & 2.875 & in. & Base case \\
\hline & ID & 2.441 & in. & \\
\hline Oil density & $\rho_{1}$ & 876 & $\mathrm{~kg} / \mathrm{m}^{3}$ & \\
\hline Gas density & $\rho_{\mathrm{g}}$ & 0.9 & $\mathrm{~kg} / \mathrm{m}^{3}$ & \\
\hline Gravity constant & $g$ & 9.8 & $\mathrm{~m} / \mathrm{s}^{2}$ & \\
\hline Oil viscosity & $\mu_{\mathrm{o}}$ & 2.32 & $\mathrm{cP}$ & \\
\hline Gas viscosity & $\mu_{\mathrm{g}}$ & 0.01442 & cP & \\
\hline Slug length & $L_{\mathrm{E}}$ & 2.53 & $\mathrm{~m}$ & $\begin{array}{l}\text { Moissis and } \\
\text { Griffith } \\
\text { (1962) }\end{array}$ \\
\hline Gas specific gravity & & 0.75 & & \\
\hline Reservoir temperature & $T_{\mathrm{r}}$ & 200 & ${ }^{\circ} \mathrm{F}$ & \\
\hline
\end{tabular}


optimization. However, the big question still arises when reservoir pressure changes are recorded and applied to the system. The behavior of the FPM after reservoir pressure declines from its original value should be analyzed in order to provide a more enlightening process on how to determine the behavior of the system. Figure 4 shows the methodology flowchart used in this study. 2.875 in. (OD)/2.441 in. (ID) of tubing size and $1000 \mathrm{psi}$ of reservoir pressure are used as the base case. The optimum gas rates are determined from GLPC for each tubing size and reservoir pressure. Then, the superficial liquid and gas velocities
$\left(\mathrm{V}_{\mathrm{sl}}\right.$ and $\left.\mathrm{V}_{\mathrm{sg}}\right)$ are derived from FPM (Daton et al. 2019). The economic limit liquid rate that used in this study is $10 \mathrm{bbl} / \mathrm{d}$.

\section{Results and discussion}

In order to provide a more detailed analysis on the future pressure decline performance of Well $\mathrm{T}$, in which the data are summarized in the table below, multiple flow pattern maps are derived for several reservoir pressure condition,
Fig. 5 Correction factor for reservoir pressure $<1000 \mathrm{psi}$
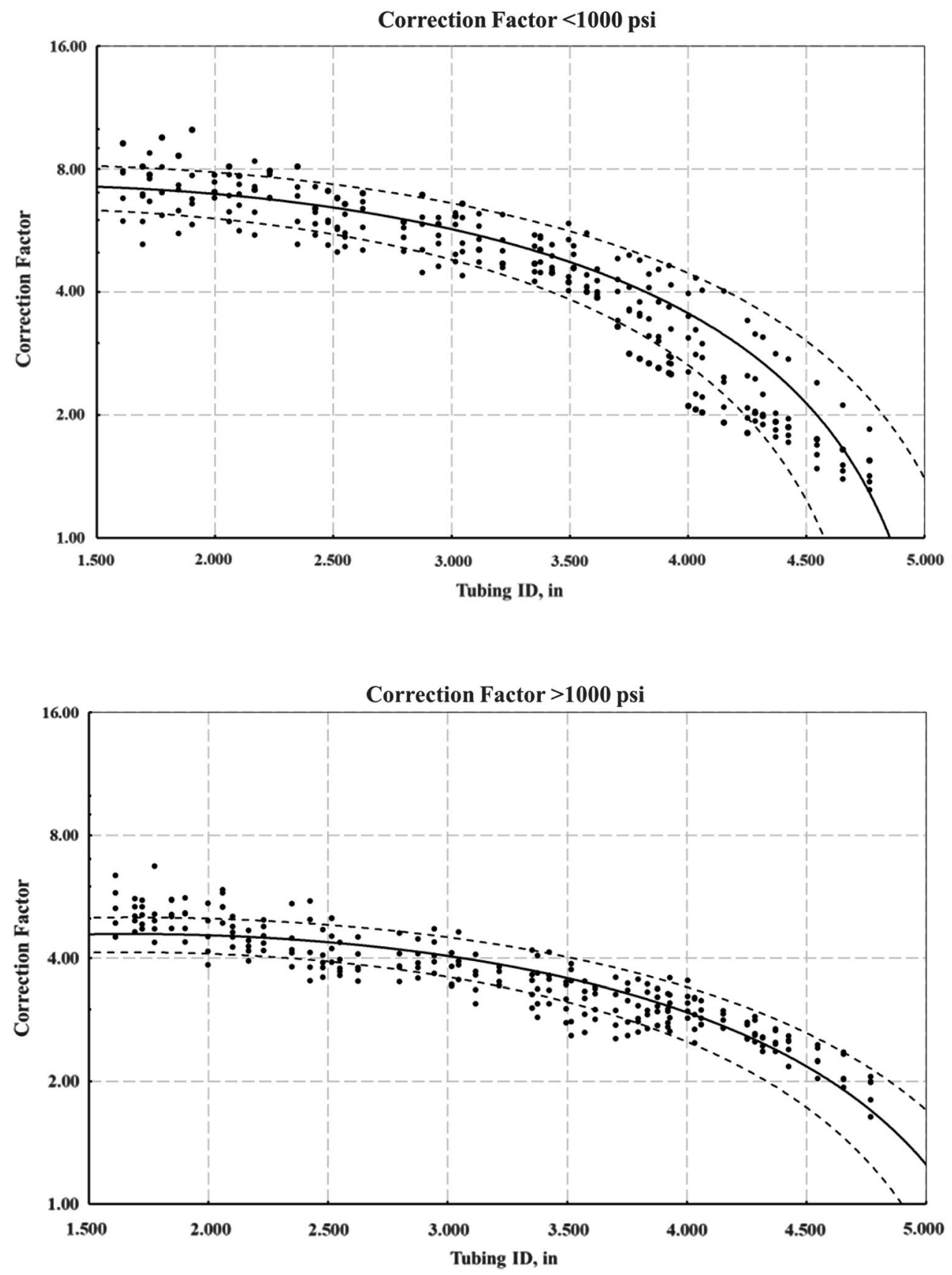

Fig. 6 Correction factor for reservoir pressure $>1000 \mathrm{psi}$ 


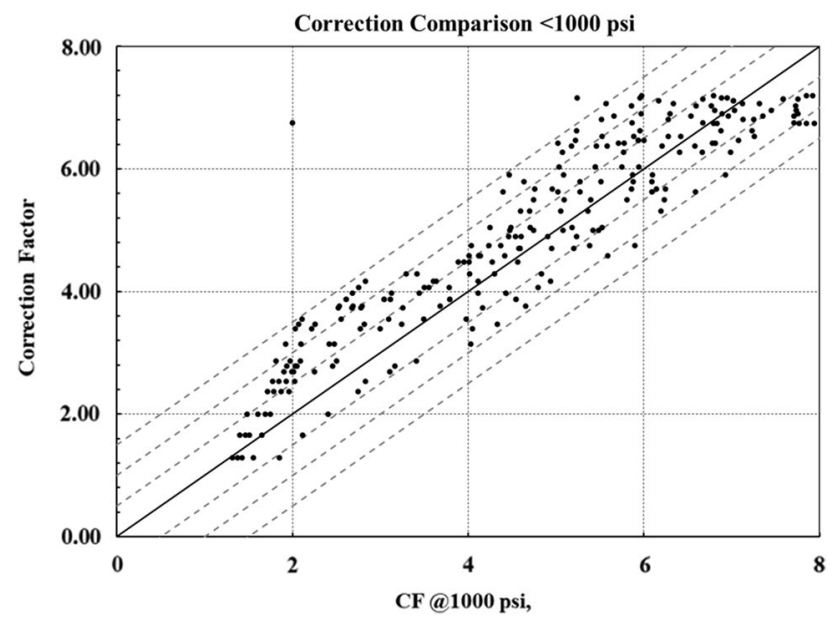

Fig. 7 Correction factor consistency for reservoir pressure $<1000 \mathrm{psi}$

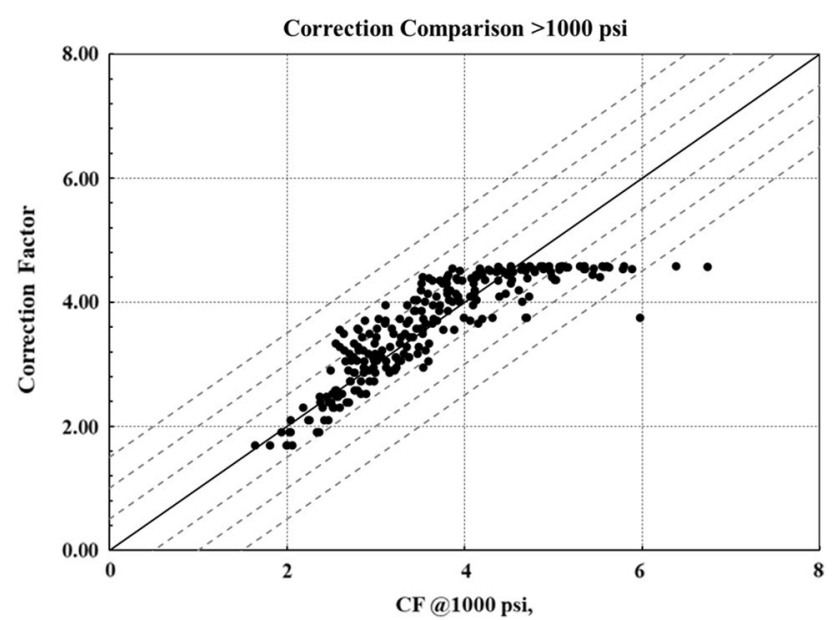

Fig. 8 Correction factor consistency for reservoir pressure $>1000 \mathrm{psi}$

i.e. $600-1500 \mathrm{psi}$, where $600 \mathrm{psi}$ is deemed the future reservoir pressure after several years after production decline (Table 1).
In order to provide a more comprehensive study on the applicability of flow pattern map in gas lift systems, a total of 520 datasets of tubing sizes, grades, and quality which responds to tubing ID are then used as the test data in this study, ranging from 2 " tubing to 5 " tubing, taken from Oilfield Tubing and Casing Database (2011).

The results of the FPM can be summarized in Figs. 4 and 5, where the multiplier corrections are then taken as a consideration for regression analysis of the optimum gas injection rate (Fig. 6).

In order to verify the behavior of the curves, a regression analysis is performed and the results shown in Figs. 7 and 8 have confirmed the accuracy of the model to be accurate, where the approximate inaccuracies in calculation can be estimated to be \pm 0.20 MMSCFD.

The flowchart presented below can be utilized to map the correction factor for analyzing the optimum injected gas rate in gas lift systems (Fig. 9).

Thus, the corrected correction factor can be translated in the following equation:

$P_{\mathrm{r}} \leq 1000 \mathrm{psi}$

$\mathrm{CF}=-0.45 \mathrm{ID}^{2}+\mathrm{ID}+7.75$

$P_{\mathrm{r}}>1000 \mathrm{psi}$

$\mathrm{CF}=-0.3 \mathrm{ID}^{2}+\mathrm{ID}+3.75$.

\section{Conclusion}

A novel perspective on mechanistic modeling application for gas lift system is presented based on the analysis of future reservoir pressure decline. Based on the results simulated, the FPM can be used for future reservoir performance with minimum alterations. The correction factor and multiplier presented in this paper can be used to estimate optimum gas lift injection rate in a faster way compared to previous practices with a relatively small error. 
Fig. 9 Flowchart for FPM and correction factor utilization

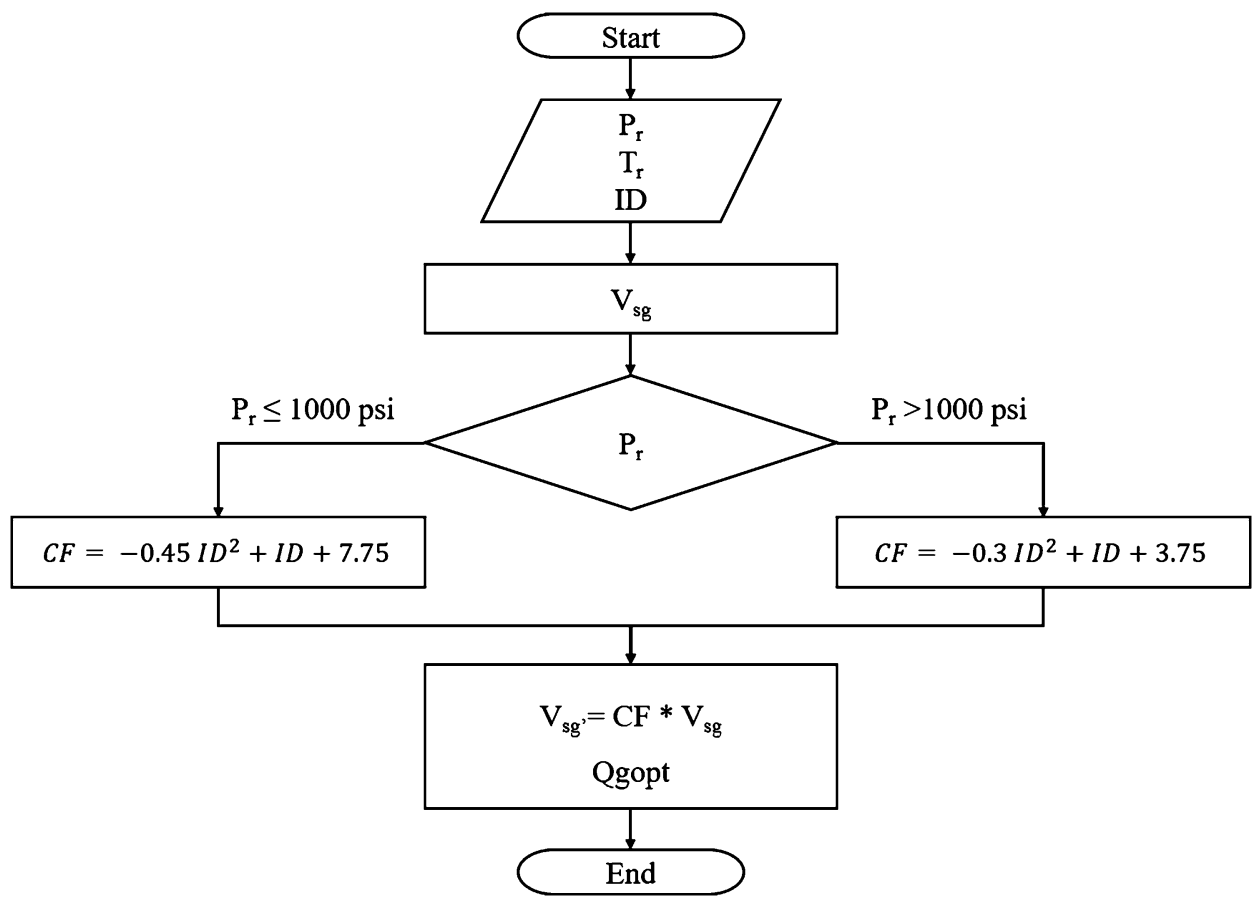

Open Access This article is licensed under a Creative Commons Attribution 4.0 International License, which permits use, sharing, adaptation, distribution and reproduction in any medium or format, as long as you give appropriate credit to the original author(s) and the source, provide a link to the Creative Commons licence, and indicate if changes were made. The images or other third party material in this article are included in the article's Creative Commons licence, unless indicated otherwise in a credit line to the material. If material is not included in the article's Creative Commons licence and your intended use is not permitted by statutory regulation or exceeds the permitted use, you will need to obtain permission directly from the copyright holder. To view a copy of this licence, visit http://creativecommons.org/licenses/by/4.0/.

\section{References}

Alarcón GA, Torres CF, Gómez LE (2002) Global optimization of gas allocation to a group of wells in artificial lift using nonlinear constrained programming. ASME J Energy Resour Technol 124(4):262-268

Ansari AM, Sylvester ND, Shoham O, Brill JP (1990) A comprehensive mechanistic model for upward two-phase flow in wellbores. Society of Petroleum Engineers

Aprilian S, Kurnely K, Novian K (2003) Rejuvenation of matured oil fields in South Sumatra, Indonesia. Soc Pet Eng. https://doi. org/10.2118/80438-MS

Arachman F, Utami F, Wasonoaji A, Tobing D (2017) Brownfield redevelopment strategies in offshore north west Java. Society of Petroleum Engineers

Asheim H (1988) Criteria for gas-lift stability. Society of Petroleum Engineers

Barnea D (1987) A unified model for predicting flow-pattern transitions for the whole range of pipe inclinations. Int J Multiphase Flow 13(1):1-12

Betancourt S, Dahlberg K, Hovde $\varnothing$, Jalali Y (2002) Natural gas-lift: theory and practice. Soc Pet Eng. https://doi.org/10.2118/74391-MS
Daton WN, Chandra S, Lumban Gaol AH, Aziz PA, Putra RA (2019) A novel fluid dynamics based for gas lift optimization. In: Proceedings ICEMINE 2019

Decker KL (2007) IPO gas lift design using valve performance. Soc Pet Eng. https://doi.org/10.2118/109694-MS

Deng L, Olalotiti-Lawal F, Davani E, Castiñeira D (2019) Hypervolume-based multiobjective optimization for gas lift systems. Society of Petroleum Engineers

Fang WY, Lo KK (1996) A generalized well management scheme for reservoir simulation. Society of Petroleum Engineers

Glass ED (1975) Continuous gas-lift theory. Society of Petroleum Engineers

Kanu EP, Mach J, Brown KE (1981) Economic approach to oil production and gas allocation in continuous gas lift. Society of Petroleum Engineers

Lu Q, Fleming G (2011) Gas-lift optimization using proxy functions in reservoir simulation. Society of Petroleum Engineers

Lumban Gaol AH, Daton WN, Aziz PA, Chandra S, Yoga HF (2019) Mechanistic multiphase flow modeling: a new approach for gas lift design using dimensionless scaling curve for tubing size optimization. In: Proceedings thermofluid 2019

Mian MA (1992) Petroleum engineering handbook for the practicing engineer, vol 2. PennWell Books, Tulsa

Moissis RR, Griffith PP (1962) Entrance effects in a two-phase slug flow. ASME J Heat Transf 84(1):29-38

Mukherjee H, Brown KE (1986) Improve your gas lift design. Soc Pet Eng. https://doi.org/10.2118/14053-MS

Nishikiori N, Redner RA, Doty DR, Schmidt Z (1989) An improved method for gas lift allocation optimization. Society of Petroleum Engineers

Posenato A, Rosa VR (2012) A genetic algorithm for gas lift optimization with compression capacity limitation. Society of Petroleum Engineers

Ranjan A, Verma S, Singh Y (2015) Gas lift optimization using artificial neural network. Society of Petroleum Engineers

Salazar-Mendoza R (2006) A new representative curves for gaslift optimization Society of Petroleum Engineers. https://doi. org/10.2118/104069-MS 
Samier P (2010) Comparisons of various algorithms for gas-lift optimization in a coupled surface network and reservoir simulation. Society of Petroleum Engineers

Schmidt Z, Doty DR, Agena B, Liao T, Brown KE (1990) New developments to improve continuous-flow gas lift utilizing personal computers. Society of Petroleum Engineers

Shoham O (2006) Mechanistic modeling of gas-liquid two-phase flow in pipes. Society of Petroleum Engineers

Taitel Y, Barnea D (1990) Two phase slug flow. Adv Heat Transf 20:83-132

Taitel Y, Dukler AE (1976) A model for predicting flow regime transitions in horizontal and near horizontal gas-liquid flow. AIChE J 22:47-55
Taitel Y, Bornea D, Dukler AE (1980) Modelling flow pattern transitions for steady upward gas-liquid flow in vertical tubes. AIChE J 26:345-354

Veeken CAM, Belfroid SPC (2011) New perspective on gaswell liquid loading and unloading. Soc Pet Eng. https://doi. org/10.2118/134483-PA

Wang P, Litvak ML (2008) Gas lift optimization for long-term reservoir simulations. Society of Petroleum Engineers

Publisher's Note Springer Nature remains neutral with regard to jurisdictional claims in published maps and institutional affiliations. 